\title{
LA SEDA CHINA EN NUEVA ESPAÑA A PRINCIPIOS DEL SIGLO XVII. UNA MIRADA IMPERIAL EN EL MEMORIAL DE HORACIO LEVANTO*
}

\author{
MARIANO BONIALIAN \\ El Colegio de México ${ }^{\mathrm{a}}$
}

Chinese Silk in New Spain at the Beginning of the Seventeenth Century.

The Imperial Vision in Horacio Levanto's Memorial

\begin{abstract}
This article analyzes the effects generated by the import and consumption of madeja silk from China in the commercial and productive level of Mexico and Spain between 1580 and 1620 . The paper questions the traditional image of an Asian trade defined by expensive, manufactured goods, oriented to an elite consumption. Considering the Memorial of Horacio Levanto (1620) and in the context of modern globalization, we propose the hypothesis that Asian trade responded to mass consumption, influencing productive structures in New Spain and Spain herself. Madeja silk from China was one of the main semi-processed goods imported via Acapulco which, as raw material, promoted the development of the Novohispanic textile industry.
\end{abstract}

Keywords: Silk madeja of China, Mexico, Industrial Development, Horacio Levanto, 1620

JEL Code: B1, B10

\footnotetext{
* Received 14 May 2015. Accepted 15 December 2015. Agradezco las finas observaciones que realizaron los revisores seleccionados por la RHE/JLAEH con vista a la publicación del presente ensayo.

a Centro de Estudios Históricos, El Colegio de México Camino al Ajusco \#20, Pedregal de Santa Teresa, Distrito Federal, México. E-mail: marianobonialian@gmail.com
} 


\section{RESUMEN}

El artículo analiza los efectos que generó la importación y consumo de la seda madeja de China en el plano comercial y productivo de México y España entre 1580 y 1620 . Se cuestiona la imagen tradicional de un comercio asiático apoyado en bienes elaborados y caros, destinados al consumo de elite. Considerando el Memorial de Horacio Levanto (1620) y en el contexto de la globalización moderna, se fundamentará la idea de que el comercio asiático respondió a un consumo masivo, llegando a influir en la estructura productiva novohispana y peninsular. La seda madeja de China fue uno los principales bienes semielaborados importados a través de Acapulco que, por ser insumos, promovieron el desarrollo de la industria textil novohispana.

Palabras clave: Seda madeja de China, México, desarrollo manufacturero, Horacio Levanto, 1620

\section{INTRODUCCIÓN}

En la actualidad, la historia global se convirtió en una de las corrientes historiográficas más convocantes. Todavía se discute si la globalización se inició hacia principios del siglo XIX, cuando Europa se colocó en el centro de la economía global, ${ }^{1}$ o en verdad apareció más temprano, cuando el mundo quedó definitivamente integrado a partir de la unión entre China y la América hispana por el Pacífico movilizando plata y bienes. ${ }^{2}$ Esta segunda perspectiva, reconoce que el comercio de la plata americana constituyó uno de los motores para las conexiones entre los continentes durante el siglo XVI. Una multiplicidad de derroteros metalíferos se crearon por las distintas áreas marítimas del globo: rutas que salían desde América hacia China por el área del Pacífico, otras redes legales y de contrabando que a través del Atlántico llegaban a Europa y las que se desprendían desde la propia Europa hacia la India y China por el Cabo de Buena Esperanza o por el Mediterráneo. ${ }^{3}$ Sin embargo, la red de circulación mundial de monedas de plata no fue la única expresión de un mundo integrado. La globalización de la época moderna no podría comprenderse sin incorporar otra variable de estudio: la circulación y el consumo de bienes. ${ }^{4}$ Los casos del oro, de la pimienta, del café, del cacao,

\footnotetext{
1 Kevin O’Rourke y Jeffrey Williamson son los principales defensores de esta tesis. O’Rourke y Williamson (2004, pp.109-177 y 1999).

2 Flynn y Giráldez (2014, pp. 29-76).

3 Existe una extensa bibliografía sobre el papel de la plata americana en la integración global de los mercados. Nombremos aquí los estudios más destacados: Cross (1983, pp. 397-423); Gunder Frank (1998); de reciente aparición: Ibarra y Hausberger, (2014).

4 Brewer y Porter (1994); Carmagnani (2012); Bethany y Yun-Casalilla, (2014).
} 
del algodón y de la seda de China manifiestan la otra cara de la globalización. Los efectos de la circulación y consumo de la seda madeja china en Nueva España a principios del siglo XvII es una problemática imperial, pero podría pensarse también como una pieza central, una fiel expresión de la «globalización blanda», primigenia. ${ }^{5}$ Fue uno de los productos más estimados en los mercados consumidores de Europa y América y el que, a través de su intercambio por la plata americana, permitió la conformación de un sistema de intercambio verdaderamente global. ${ }^{6} \mathrm{Su}$ alto consumo por Hispanoamérica y Europa permitió que a China erigirse como el depósito mundial de las monedas de plata de a ocho reales españoles, incluso superando a Europa. ${ }^{7}$

El comercio del galeón de Manila cumplió un papel en ese temprano mundo globalizado. ${ }^{8}$ Su resonancia no se limitó al trayecto entre Acapulco y Manila, sino que influyó en el desarrollo de redes comerciales por el este y sudeste asiático ${ }^{9}$ y por Hispanoamérica, desde México hasta Buenos Aires. ${ }^{10}$ La historiografía ha concebido el comercio transpacífico como un tráfico suntuario y de elite, donde los bienes llegados desde el Oriente al puerto de Acapulco fueron exclusivamente objetos acabados, de alta calidad, caros y para el consumo de un grupo "selecto» de la sociedad hispana. El consumo de las sedas y porcelanas asiáticas denotaría ese perfil «extravagante», de una cultura material marginal, sin la capacidad para incidir en la economía productiva novohispana. Según esta interpretación, la influencia de la cultura oriental por Nueva España sólo repercutió en el minúsculo mundo consumista y en la cultura material de las elites.

El presente ensayo aspira a revisar la tradicional definición. Con documentación preferentemente cualitativa, se fundamentará que desde finales del siglo Xvi dicho eje movilizó seda y algodón oriental en forma de hilo, barata, un producto no terminado, que generó importantes efectos en la estructura productiva de Nueva España y en el mercado consumidor hispanoamericano. El ensayo está organizado en dos apartados. En el primero se estudia el papel que adquirió la importación de seda china en madeja por Acapulco con vistas a comprender el estancamiento de la sericultura novohispana registrada en la segunda mitad del siglo xvI y la expansión de los obrajes en las primeras décadas de la centuria siguiente. Se ha considerado que el abandono de las plantaciones de moreras y crías de gusano de seda en Nueva España obedeció a una política prohibicionista

5 Este temprano fenómeno planetario se lo conoce como Soft Globalization. De Vries (2010, 710-733).

6 Von Glahn (1996); TePaske (1983, pp. 425-445); Flynn y Giráldez (1997); Lee (1999, pp. 2-26); Pomeranz (2000).

7 Barret (1990, pp. 240-252); Gunder Frank (1998, pp. 143-150); Marichal (2006, pp. 25-52).

8 Flynn y Giraldez (2014, pp. 29-76).

9 Gipouloux (2009).

10 Bonialian (2014). 
peninsular. La historiografía nos ofreció una explicación idéntica para entender la disminución en la confección de tejidos novohispanos de sedas. Aquí se propone una explicación alternativa para comprender ambos fenómenos, revalorizando la importación novohispana de seda madeja de China por el Pacífico. En el segundo apartado se analiza la mirada brindada desde España sobre el comercio y consumo de la seda madeja de China por el virreinato novohispano y sus efectos disruptivos sobre el mundo trasatlántico y el sistema productivo peninsular. Una de las explicaciones más finas y sólidas de la problemática la brindó el comerciante genovés Horacio de Levanto hacia 1620. El análisis del Memorial brinda nuevas pistas acerca del papel protagónico que llegó a tener la seda china en la economía de la Monarquía hispánica y en el comercio global.

\section{LA SEDA CHINA, EL GALEÓN DE MANILA Y LA SERICULTURA NOVOHISPANA}

Un estudio que intente analizar las implicancias de la comercialización de la seda madeja de China por España e Hispanoamérica necesita, ante todo, rastrear la evolución de la política metropolitana con relación a la industria textil. Vale considerar la periodización sugerida por Miño Grijalva (1988, pp. 292-294) sobre la actividad. Habrían existido dos períodos claramente definidos. La primera etapa abarcó desde 1530 hasta 1570, período en el que la Corona otorgó libertades para la producción textil por las Indias. Ante el temor que los obrajes españoles se vean incapacitados para responder simultáneamente al mercado interno y ultramarino, el Consejo de Indias decidió el cierre a la exportación de los tejidos producidos en la Península. La industria española, dependiente de la producción inglesa, francesa y holandesa, no estaba preparada para abastecer su mercado interno y aún menos el de las colonias hispanoamericanas. La decisión habría redundando en un claro beneficio para la producción de materias primas en las Indias. La sericultura novohispana fue un caso representativo de la promoción manufacturera en Hispanoamérica. Hacia 1536, el primer virrey Antonio de Mendoza plantó árboles de moreras en Huejotzingo, Cholula y Tlaxcala para la crianza del gusano de seda. ${ }^{11}$ Años después, en 1540, se erigió en la Mixteca Alta de Puebla el centro de producción de sedas más importante del virreinato. En 1548 Puebla gozó de la autorización real para la fabricación de tejidos de seda. No resulta casual que fuera la Mixteca Alta el lugar de promoción más importante del virreinato de la sedería. Ante la lejanía de los centros mineros, los indígenas encontraron en la sedería una lucrativa

\footnotetext{
11 «Plantación de moreras: Huejotzingo, Cholula y Tlaxcala», Archivo General de Indias (AGI), Patronato, 180, R. 68.
} 
actividad para la obtención de metálico que les permita cumplir con las obligaciones tributarias exigida por los encomenderos. ${ }^{12}$

Hacia finales del siglo XVII la política española tomará un curso opuesto. Desde 1570 hasta 1630 se emitieron medidas restrictivas y de prohibición para frenar la expansión de la industria textil local. Mediante disposición real, España comenzó a reconocer que la relación colonial sólo podía mantenerse si los mercados hispanoamericanos eran abastecidos de productos españoles y europeos. El monopolio comercial, movilizando plata hacia España y bienes manufacturados hacia las Indias, era la herramienta más adecuada para lograrlo. Assadourian (1982, pp. 191-207) nos ofreció una interpretación acerca del curso de la política peninsular sobre la producción manufacturera en las Indias. Señaló que la prohibición se aplicó en los obrajes donde se labraban textiles de alta calidad, un mercado consumidor que debía reservarse a los textiles elaborados de España y Europa. Mientras que sí se autorizó el desarrollo de centros manufactureros dedicados a confeccionar vestidos y tejidos para el uso de los sectores sociales de escasos recursos. Pero la dominación encontraba límites a partir de la debilidad estructural del aparato manufacturero español. El atraso industrial peninsular obligaba a que la demanda hispanoamericana se abasteciera de textiles europeos no españoles. Las flotas que se dirigían a Nueva España tenían una mayoritaria carga de textiles producidos en Inglaterra, Francia y Holanda.

Si existió un caso que escapó a la regla general fue el de la seda española. Desde el siglo XvI, Toledo, Granada, Murcia, Valencia y Sevilla presentaban una producción de tejidos de seda significativa, con capacidad para responder su mercado interior como para la exportación. Para garantizar su venta en el mercado novohispano, España debía prohibir la producción de las moreras y la cría del gusano en el virreinato, disposición real que se dictó en 1596. ${ }^{13}$ Pero: ¿ sólo el peso de una normativa fue la responsable del descenso de la producción de seda por Nueva España a principios del siglo XVII? Una razón, quizá de mayor peso, se encontraría en la importación de seda china por el puerto de Acapulco. Desde 1570 el comercio transpacífico comenzó a cobrar una importante repercusión no sólo en la economía novohispana, sino también en el comercio español trasatlántico. ${ }^{14}$ Las exportaciones de plata peruana y novohispana hacia China con el consecuente ingreso de una canasta de artículos de origen asiático al mercado mexicano se convertían, según los comerciantes peninsulares, en los dos más importantes factores de las escasas ventas de tejidos peninsulares y europeos en la feria de Veracruz.

12 Borah (1963, pp. 1-15).

13 Pérez Herrero (1983, pp. 109).

14 La literatura sobre el galeón de Manila es extensa y sería imposible reproducirla por completo aquí. Los más trascendentes serían: Schurz (1960); Chaunu (1960); Flynn y Giráldez (1997); Yuste (1984); Resultan sugerentes algunos ensayos compilados por Bernabeú y Shaw (2013); Bernal (2004, pp. 485-525); Bonialian (2012). 
TABLE 1

PROCEDENCIA Y CANTIDADES DE LAS MERCADERÍAS EMBARCADAS EN EL GALEÓN DE MANILA RUMBO AL PUERTO DE ACAPULCO

\begin{tabular}{|l|c|c|c|c|c|c|}
\hline & \multicolumn{2}{|c|}{1581} & \multicolumn{2}{c|}{1587} & \multicolumn{2}{c|}{1595} \\
\hline Procedencia & Unidades & $\%$ & Unidades & $\%$ & Unidades & $\%$ \\
\hline China & 40 & 51,9 & 278 & 57,8 & 1368 & 91,8 \\
\hline Filipinas & 37 & 48,1 & 203 & 42,2 & 121 & 8,2 \\
\hline Totales & 77 & 100 & 481 & 100 & 1489 & 100 \\
\hline
\end{tabular}

Fuente: Álvarez (2013), p. 71.

En este sentido, vale atender las importaciones de seda china por Acapulco. El estudio realizado por Luis Alonso Álvarez (2013, p. 71) constata que entre 1565 y 1590, las importaciones por Acapulco estaban compuestas, casi de manera equitativa, por productos de origen filipino y chino. Las cartas del virrey Martín Enríquez (1568-1580) dan cuenta que si bien la seda china era un producto muy demandado en México, no fue ni el único artículo ni el principal de los cargamentos por esas décadas. ${ }^{15}$ El siguiente cuadro de Álvarez de los galeones de 1581,1587 y 1595, en el cual el criterio unidades se refiere a mercancías nos ahorra de varios comentarios:

Recién en 1595 las importaciones novohispanas por el galeón de Manila fueron predominantemente productos de origen chino, mientras que lo producido en las propias filipinas alcanzaba un reducido $8.2 \%$. Esa mayoritaria importación de origen chino (91.8\%) se componía de sedas y loza. La documentación que utiliza Álvarez no permite discriminar la tipología de la seda comercializada. Sin embargo, como se verá más adelante, el tipo de seda que prevalecería fue la seda de hilo procedente de Lanquín (Cantón), dispuesta para su elaboración como tejido. La seda de hilo era la que se recogía en vueltas para luego devanarse fácilmente y convertirla, con el trabajo del obrajero y del telar, en una prenda; estamos ante lo que en la época se llamó la seda madeja de China.

En estas condiciones, dos frentes de acción se ejecutaron desde la Península. Por un lado, se decidió por una política de regulación sobre el comercio del galeón de Manila. Nos referimos a la famosa normativa de 1593 que, entre otras cláusulas, reducía a tan sólo 250 mil pesos las mercaderías chinas, particularmente la seda bruta y labrada, que podían importarse por el puerto de Acapulco para el consumo novohispano. Si en años previos, el trato con Filipinas y China era libre, ahora Perú y Centroamérica quedaban marginados de la contratación de la China. ${ }^{16}$ El otro frente de acción se

\footnotetext{
15 Véase por ejemplo: AgI, México, 19, documentos 116, 142 y 74.

16 AGI, Filipinas, 339, L.1, f. 72-75. Para conocer los pormenores de esta normativa: Álvarez (2013, pp. 67-68).
} 
aplicó en el año 1596, con la prohibición para la producción y la cría de gusano en México. Sería difícil pensar que la ofensiva legislativa peninsular fue la causa para el abandono de las plantaciones de moreras y de la cría del gusano de seda en territorio novohispano. Aquí se sugiere que el fenómeno habría obedecido al sistemático ingreso de la seda madeja de China, lista para trabajarse en los obrajes novohispanos. En otros términos, el descenso de la producción de seda madeja novohispana no provocó una baja de la producción textil sino que, por el contrario, propició su funcionamiento. Lo que sucedía era que, por razones de costos, la seda no se producía en suelo novohispano, sino que se importaba con el galeón de Manila. El abandono de la sericultura novohispana, más que verse condicionada por una normativa peninsular, habría obedecido a una decisión novohispana de priorizar el insumo importado desde China. Por lo tanto, tres fenómenos se desenvolvieron en simultaneidad: a) el incremento relativo en los ingresos (lícitos e ilícitos) de la seda madeja de China a través del galeón de Manila; $b$ ) el abandono de los cultivos de las moreras en el virreinato de Nueva España; c) una tendencia al aumento de los obrajes por México que contaba, como uno de sus principales suministros, la seda madeja del Oriente.

La seda madeja de China condicionaba la producción local de las islas Filipinas. Hacia finales del siglo, el artículo era importado a través de pequeñas embarcaciones chinas desde Cantón, provocando que los propios indígenas abandonaran el uso de las telas locales. ${ }^{17}$ En 1588, el primer obispo de Manila, Domingo de Salazar, decía que era tanta la seda venida de China que lograba responder no sólo a los pedidos del archipiélago español sino a la demanda del mercado novohispano. ${ }^{18}$ Con vistas a proteger la producción local, en 1590 el gobernador de Filipinas, Gómez Pérez das Mariñas, emitió una orden para que los «naturales» no vistan sedas ni ropa de la China. ${ }^{19}$ Casi veinte años después, en 1613, los efectos que generaba el ingreso del textil asiático continuaba preocupando al Cabildo de Manila porque sus indígenas preferían hilvanar sus vestidos con seda de China antes que cultivar sus tierras. ${ }^{20}$ La situación no resultaba diferente en suelo novohispano. Juan Grau y Monfalcón, procurador general de las islas Filipinas en 1637 reconocerá en su Memorial dado al Rey ${ }^{21}$ la íntima dependencia de los telares novohispanos con la seda madeja de China:

\footnotetext{
17 Lanes y Duval (1787, p. 31).

18 «Informe del obispo de Manila, Domingo de Salazar, sobre el censo de las islas Filipinas. Manila» (1588), Agi, Filipinas, 14, s/n de fs.

19 AGI, Filipinas, 6. R. 7, $\mathrm{N}^{\circ}$ 63. "Modo en que han de vestir los pobladores de Tierra Firme» (1513), AGI, Panamá, 233, L. 1, fs. 61-64; «Prohibición de usar prendas de sedas en Indias» (1509), AGI, Indiferente, 418, L. 2, fs. 87-89.

${ }^{20}$ "Petición del Cabildo secular de Manila sobre no cultivar los indios», AGI, Filipinas, 27, N. 89.

21 «Memorial dado al Rey en su Real Consejo de las Indias por D. Juan Grau y Monfalcon, procurador general de las Islas Filipinas, sobre las pretensiones de la ciudad de Manila y demás del archipiélago en su comercio con Nueva España», Colección de Documentos inéditos relativos al
} 
«Se sabe que la seda en madeja de China es más pareja y limpia para tejidos delgados y llanos que la mística que se cría en aquél reino [México] demás de ser esta menos de la que ha menester la tierra. Y de este trato y obras se sustentan en México, la Puebla y Antequera más de catorce mil personas con sus telares y aprobado todo por cédulas Reales» ${ }^{22}$

La seda novohispana seguirá produciéndose, pero no será suficiente para abastecer los pedidos del mercado novohispano. Ni menos aún el peruano que, como nos enseñó Assadourian (1982, pp. 131-221), constituyó un mercado autosuficiente, pero que requirió de dos necesidades principales del exterior: el lino y la seda. Lo cierto es que a pesar de la tendencia decreciente de la producción de seda novohispana, desde finales del siglo xvi los obrajes cobrarán nuevo impulso a partir del suministro de la seda madeja asiática. En 1597, en la ciudad de Los Ángeles, en Puebla, existían 34 obrajeros que contaban con un total 215 telares en los que, en algunos de ellos, se labraban vestimentas y otros tejidos de paños y bayetas compuestos del insumo oriental. ${ }^{23}$ Siete años después, en 1604, cuando se emitió la prohibición para enviar artículos asiáticos desde Acapulco hacia el Perú, el virrey novohispano Montesclaros, defensor de la reapertura del comercio interamericano por el mar del Sur, señalaba que los algodones de la India y de las islas Filipinas como así también la seda madeja china constituían un medio indispensable para el funcionamiento de los 110 obrajes que existían en toda Nueva España, donde el número de la mano de obra rondaba entre 50 y 100 por cada centro manufacturero. ${ }^{24}$ Más tarde, en 1637, Grau y Monfalcón, en su otro famoso documento sobre Justificación y Conservación de la Monarquía, defenderá la posición sostenida por los mercaderes de México y Perú sobre la apertura del tráfico asiático entre ambos reinos. Contradiciendo el argumento peninsular, replicará que el cierre hacía peligrar los puestos de trabajo de 14 mil personas dedicadas a la actividad textil porque los tejidos que elaboraban estaban compuestos con seda china y eran exportados hacia el Perú y Tierra Firme. De tal manera, las autoridades aduaneras tenían serias dificultades para identificar lo que estaba autorizado para circular como producción local novohispana y lo procedente de China que estaba prohibido. ${ }^{25}$ Se trata, desde luego, de un problema que afectaba no sólo al plano comercial sino también al productivo. Un corte de seda de origen chino

\footnotetext{
(footnote continued)

descubrimiento, conquista y organización de las antiguas posesiones españolas de América y Oceanía, por Luis Torres de Mendoza, Madrid, 1866, tomo VI, 1637, fs. 345-483.

22 Grau y Monfalcon, "Memorial dado al Rey», fs. 474-475.

23 "Carta del virrey de Monterrey», AGI, México, 23, N. 86, fs. 102-103.

24 La lista detallada: México 25 obrajes de paños y 10 de sombreros; Escapucalco: 2 de paños; Tlaxcala: 7 de paños, 4 de sayales y 2 de trapiches; Tepeaca: 5 de sayales; Puebla: 35 de paños; Cholula: 6 de paños; Tezcuco: 8 de paños; Sarchimilco: 4 de sayales y Zayala: 4 de sayales. En Relación de los obrajes que se encuentran en el reino de Nueva España por el Virrey, 10 de mayo de 1604, AGI, México, volumen 26, núm. 19: 19-21.

25 Grau y Monfalcón [1637], 1734: 44-78.
} 
que llegaba a Acapulco desde Manila era un objeto de comercio intercontinental, pero al ser reexportado desde Acapulco a Perú, el bien no sólo formaba parte del comercio interamericano sino que, más importante aún, podía ser considerado como un producto de origen novohispano. Esta suerte de mutación en cuanto a la procedencia, hacía que un objeto ilegal circulara y fuera consumido de manera legal por cada rincón de Hispanoamérica.

\section{ESPAÑA Y LA SEDA MADEJA DE CHINA: EL MEMORIAL DE LEVANTO}

El problema del comercio de la seda madeja de China no se circunscribió a las fronteras novohispanas; sus importaciones a España también fueron significativas. El insumo oriental será durante el todo el sigo xVII un rubro de importación dominante en la Europa occidental, peligrando el desarrollo de la industria sedera en Holanda, Francia e Inglaterra, hasta el punto que sus estados buscarán implementar una política proteccionista por medio de leyes prohibitivas (no siempre exitosas) para su ingreso. En España se vivió un fenómeno similar porque por estos tiempos se analizaron medidas para contrarrestar la sistemática importación que se hacía de la seda china. El artículo podía alcanzar el mercado español por dos principales vías: por el tráfico directo euro-asiático de la ruta del Báltico o del Cabo de Buena Esperanza o por la vía atlántica. Las redes de comercio por el Mediterráneo operadas por armenios desde Marsella fue una puerta de entrada del textil oriental. ${ }^{26}$ No debemos olvidar que desde el frente europeo las casas comerciales extranjeras instaladas en España que respondían a las compañías europeas del Oriente también contribuyeron a la circulación de la seda china por España. El otro gran frente de importación provino desde la propia Nueva España, desde Veracruz, a partir de los excedentes que disponía el virreinato. Como una suerte de correa, la seda madeja se movía por el virreinato hacia el eje trasatlántico que conectaba a Veracruz con Sevilla. ${ }^{27}$ En las primeras décadas del siglo España debatía sobre los mecanismos necesarios para controlar el comercio de la seda madeja asiática por la Monarquía, no sólo por los efectos disruptivos que ocasionaba en Nueva España, sino porque comenzaba a desplazar a la seda española de su propio mercado interno. ${ }^{28}$

Ante la competencia, aparecieron proyectos y planes para reemplazar la importación española de la seda china de hilo por la propia semilla de la región de Lanquín (Xauquin), de Cantón. ${ }^{29}$ Hacia 1610, el procurador

26 Gipouloux (2009, pp. 113-156).

27 "Carta del virrey marqués de Cerralbo», (1631), AgI, México, 31, No 1, s/n de fs. García Fuentes (1997, p. 214) constata que hacia el año 1589, la flota de Martín Pérez de Olazabal llevó a Sevilla más de 15 mil libras de seda China.

28 Bernal (2005, p. 262).

29 Sería Xauquin, región de Cantón. 
general de las Islas Filipinas, Fernando de los Ríos Coronel, recomendó el traslado de la semilla desde China hacia España porque era de mejor calidad que la local, al ser «muy fecunda y los gusanos hacen capullos muy grandes». Según Ríos Coronel, el clima de Lanquín era muy similar al español, por lo que la semilla respondería de manera excelente a las tierras de Granada, Valencia o Murcia. ${ }^{30}$ El gobernador de Filipinas, Juan de Silva, consideró oportuna la propuesta del procurador y le solicitó un minucioso informe sobre las tipologías y técnicas que se utilizaban en Oriente para su cultivo en los campos españoles. Desconocemos si este proyecto se llevó a la práctica o cayó en el olvido. ${ }^{31}$

Para los vecinos de Granada, Valencia y Murcia, principales centros productores de seda en España, la importación del insumo asiático resultaba un golpe de gracia. Si bien no contamos con fuentes cuantitativas que ilustren con exactitud las cantidades importadas por aquél abanico de flujos, en su conjunto habrían incidido significativamente en la evolución de la sericultura española. En 1617, los "vecinos de Castilla» presionaban a la Corona por el cumplimiento de una ley (que no hemos logrado comprobar su existencia en los documentos) que prohibía el ingreso de «seda de China y de Persia» en España. ${ }^{32}$ Decían que los campos de cultivo de seda en Granada, Murcia y Valencia iniciaron un proceso de decadencia y abandono a raíz de la entrada de la seda en mazo, torcida y madeja de China; un textil "falso» que al utilizarse como insumo arruinaba la prenda de tejido confeccionada en las fábricas de Toledo, Sevilla y Córdoba. Señalaban que su baratura se explicaba por la calidad tan ordinaria y, por ende, su éxito en el mercado. Los vecinos de Sevilla no dudaban que "el esquilmo de seda que en estos reinos hay es tan grandioso que basta no sólo con lo que han menester, sino que se puede sacar cantidad fuera de ellos». ${ }^{33}$ Aquí tocamos un planteo que causó gran controversia en su momento. En el Memorial de Horacio Levanto, del que nos ocuparemos enseguida, se señala que la sericultura peninsular no sólo no tenía capacidad de exportación sino que tampoco cubría la oferta del mercado peninsular. Para el genovés, los productores de Sevilla situaban el debate entre la elección de un reino imaginariamente productivo o una Castilla meramente beneficiosa para «arrendadores» o mercaderes de ultramar, que ponían en peligro la supervivencia de la sericultura local y la acumulación de metales en el reino.

Un informe muy similar al de los vecinos de Castilla aparecía en el año 1628. El escrito lleva la firma de Juan Velázquez de Madridejos en el que se identificaban las razones de la prohibición a la entrada de la seda

\footnotetext{
30 «Petición de Ríos Coronel sobre variedad de seda de China» (1609), AGI, Filipinas, 27, N. 72, fs. $513 \mathrm{r}-514 \mathrm{v}$.

31 «Orden de enviar a España semilla de seda china» (1610), AGI, Filipinas, 329, L. 2, f. 118.

32 «Memorial del Reino (de Castilla) pidiendo la prohibición de la importación de seda de China y Persia», AGI, Patronato Real, Leg. 89, exp. 298, fs. 760-761.

33 Ibídem, f. 760.
} 
China. ${ }^{34}$ Allí se sostenía que la suma del pago de almojarifazgo y alcabala que pesaba sobre el textil de China, un textil «forastero», era inferior a los costos de producción y comercialización que pesaban sobre la seda local de Granada. A pesar de la aspereza y de la inferior calidad, la baratura de la seda madeja de China ponía en peligro la subsistencia de las familias de Granada. Sus tierras se habían dado a censo, pagando unos 100 mil ducados anuales gracias a la actividad de la sericultura. Hacia 1628, los vecinos de Granada habrían estado adeudando al fisco real unos 200 mil ducados del censo porque sus ventas se veían disminuidas dada la competencia exitosa de la importación de la seda asiática al mercado español. ${ }^{35}$

Uno de los análisis más serios para intentar solucionar los problemas que suscitaba el comercio de la seda madeja de China por México y por el conjunto espacial de la Monarquía es el que realizó el genovés Horacio Levanto. Se trata del Memorial sobre el trato de la China con Nueva España y estos reinos, impreso entre los años 1620 y $1622 .{ }^{36}$ Ubicado en la corriente arbitrista española, merece consideración por una razón sencilla: Levanto fue un claro conocedor de lo que acontecía en la contratación asiática por haber residido varios años en México. Sabemos que pocos pensadores del siglo XVII cumplían con el principio de informar en base a la experiencia personal, como testigo ocular del hecho. ${ }^{37}$ Desde 1594 residió durante 15 años en la ciudad de los Ángeles de Puebla; uno de los más importantes polos obrajeros novohispanos que, como apuntamos, concentraba gran parte de la seda china madeja importada. Levanto llegó a ocupar el cargo de fundidor de la Casa de Moneda de México. ${ }^{38}$ Familiarizado con el trato en metálico, se dedicó al comercio marítimo novohispano de larga distancia, con las Islas Filipinas y con las flotas de Veracruz. El ser testigo ocular, le permitió conocer con sumo detalle: a) la composición de la canasta filipina de exportación del galeón de Manila; b) la tipología de la seda china ingresada por Acapulco; c) sus circuitos de comercialización, tanto internos como externos y d) el público social interesado en su consumo. En 1610 se mudó a Sevilla, contando con carta de naturaleza. ${ }^{39}$ Allí afianzó su imagen pública y una reconocida posición en el

\footnotetext{
34 «Razones de conveniencia que hay para que no se deba permitir, antes prohibirse, la entrada de la seda de la China, y demás mercaderías de ella en las Indias y en estos reinos; y los daños e inconvenientes que se siguen de no prohibirse de todo punto, y de su contratación», AGI, Filipinas, 40 , N. 5, fs. $1-4$.

35 Ibídem, fs. 3-4.

36 El manuscrito completo puede verse en el portal de la Biblioteca Digital Nacional de España (BN), con la clasificación R/17.270. Levanto dirigió sus reflexiones al «Señor Don Fernando Carrillo, Caballero del hábito de Santiago y Presidente del Real y Supremo Consejo de Indias» entre 1617 y 1622. Como bien lo revela Díaz Blanco (2014, p. 55) la obra pudo haber adquirido una clara funcionalidad dentro de un proceso de decisiones institucionales. No sólo por estar dedicado al consejero de Indias, sino porque la obra denota una revisión del propio Levanto ante observaciones del Consejo de Indias.

37 Díaz Blanco (2014, p. 57)

38 AGNM, Real Hacienda, Casa de Moneda, vol. 429, exp. 1, fs. 2-306.

39 AGI, Indiferente, 449, L. A 2, F.148-148V.
} 
comercio de la Carrera de Indias. Llegó a ser medidor de alhóndiga, tesorero de la Casa de Moneda de Sevilla y, apoyado en un gran capital mercantil, uno de los principales cargadores sevillanos en las flotas dirigidas hacia Nueva España. ${ }^{40}$ En resumidos términos, el Memorial podría abordarse a partir de dos niveles de análisis: su vida México le permitió denunciar el grave problema que suponía la concentración de la seda china por el virreinato y, al momento de mudarse a España, asumió la defensa peninsular, ideando un plan para desplazar la centralidad que gozaba México en el comercio asiático.

A pesar de las limitaciones y los tiempos en la circulación de la información, asombra la percepción planetaria de Levanto. El trato asiático se convertía en un juego mercantil en el que se veían involucrados los espacios de China, Japón, la India Oriental, Filipinas, México, Perú, Panamá, España y la Europa occidental. Constituía un problema global, que superaba las fronteras políticas y económicas de naciones, monarquías y virreinatos. Todo comenzaba, según Levanto, en el tramo que iba desde las costas de China hasta Filipinas, cuando «muchos [comerciantes] chinos que llaman sangleyes» cargaban hacia Manila algodón y seda. ${ }^{41}$ ¿Cuáles eran estos textiles? No ahorra detalles en la tipología de los artículos movilizados. En cuanto sedas había terciopelo llano, labrado, rasos, damascos, gorgaranes [sic], tafetanes, picotes, tocas, medias, seda floja y torcida y, por sobre todo, de madeja "que es la que se hace todo lo dicho». ${ }^{42}$ En el rubro algodón sobresalían las sinabafas, ${ }^{43}$ bocacies ${ }^{44}$ [sic], olandillas y caniquies. ${ }^{45}$ Completaban la carga hacia Filipinas las «camas, pabellones, sobrecamas, almizcle, loza y otras cosillas». Todas estas sedas y tejidos de algodón se navegaban para Nueva España, agregándose, en menores dimensiones y como "comercio propio», otros lienzos de algodón que se tejían en la isla de Luzón, como lampotes, mendinaques, ${ }^{46}$ mantas de Moro, de Bombón y de Ilocos. Por último, había un minúsculo espacio en el galeón de Manila para la cera en pan (amarilla y blanca), arroz en cáscara y limpio, vino de palmas, sal, cera, aceite, gallinas, pimienta, clavo de islas Molucas, nuez moscada, ganado de cerdo y vacuno. ${ }^{47}$ Levanto subrayaba que los bienes producidos en las Filipinas y traficados hacia el puerto de Acapulco eran la minoría, producto

\footnotetext{
40 La gran fortuna que llegó a concentrar Horacio Levanto se confirma en su inventario posmortem de 1642: AGI, Contratación, 966, N.2, R. 2. Sobre sus capitales invertidos en las flotas atlánticas: García Fuentes (1977, p. 205 y 234); Díaz Blanco (2014, pp. 57-58).

41 Memorial, f. 1.

42 Decía Levanto: «de algunos años a esta parte han traído la dicha seda madeja desbanada [sic], hecha pelos y tramas, felpas y otras obras nuevas». Ibídem, f. 2.

43 Tela parecida a la Holanda, que no tiene otra tintura ni color más que el suyo natural. Lo que sigue del Diccionario Real de la Academia Española.

44 Bocací. Tela de lino engomada más gorda y basta que la holandilla.

45 Caniquí. Especie de lienzo delgado que se hace de algodón y que provenía, en general, de la India.

46 Tela resistente de algodón.

47 Memorial, f. 2.
} 
de la paga de tributos de los indígenas, con lo que viene a confirmar la hipótesis señalada en páginas anteriores por el historiador Alonso Álvarez. ${ }^{48}$

Juan Grau y Monfalcon, el procurador general de las islas Filipinas de esos tiempos, atendió el informe de Horacio Levanto, hasta el punto de reproducir grandes párrafos del genovés en su propio Memorial de $1637 .{ }^{49}$ Tomando las ideas de Levanto llegó a decir que los géneros «se dividen en seis suertes»: a) la seda, en madeja, peso y trama; $b$ ) los tejidos de seda; $c$ ) los tejidos de algodón; $d$ ) frutos de la isla; $e$ ) brujerías y regalos. Los dos últimos rubros eran necesarios y no provocaban un daño al comercio español con las Indias. Mientras que las producciones locales del archipiélago contribuían a su desarrollo económico interno, el mobiliario, la cerámica y otros bienes «curiosos» eran realmente escasos, de poca gravitación, ya que España no tenía ninguna posibilidad de producir. ${ }^{50}$ Todo lo contrario sucedía con los tejidos de seda, la seda madeja y los tejidos de algodón. Según Levanto, esta canasta de textiles representaba, prácticamente, la totalidad de la carga; «a veces en partes iguales $\mathrm{u}$ otras más de una que otra». ${ }^{51}$

$\mathrm{Su}$ atracción en el mercado americano se explicaba por la perfecta combinación de baratura y calidad; imposible para que los productos europeos llegados por el puerto Veracruz pudieran competir. Una gama de atributos hacían de la seda y el tejido de algodón algo inigualable, que sólo el clima y la economía china podía brindarlo. El algodón era resistente y se lavaba con facilidad, mientras que la seda se producía gracias a unos fuertes árboles de moreras que no crecían en otros lugares. Sus capullos eran relativamente durables y con una blancura especial. ${ }^{52}$ Más adelante veremos que Levanto no creía que la semilla de china llegara a reproducirse en tierra peninsular, como sí lo suponían los informes de funcionarios que fueron mencionados más arriba. La baratura de los productos se explicaba por sus costos, tanto de producción como de comercialización:

«en China hay tanta abundancia de trabajadores $\mathrm{y}$ un tejedor $\mathrm{u}$ otro oficial trabaja un mes por cuatro reales, sale la ropa tan barata que si la cantidad que va a Nueva España viniera a esta ciudad de España descompusiera más de lo que está el trato de la seda de Granada, Toledo y las demás partes de estos reinos » ${ }^{53}$

\footnotetext{
48 Memorial, f. 2.

49 «Memorial dado al Rey en su Real Consejo de las Indias por D. Juan Grau y Monfalcon, procurador general de las Islas Filipinas, sobre las pretensiones de la ciudad de Manila y demás del archipiélago en su comercio con Nueva España», Colección de Documentos inéditos relativos al descubrimiento, conquista y organización de las antiguas posesiones españolas de América y Oceanía, por Luis Torres de Mendoza, Madrid, 1866, tomo VI, 1637, fs. 345-483.

50 «la gruesa se reduce a los tejidos de seda y algodón, porque lo demás de curiosidad o regalo es poco y de poca salida», en "Memorial dado al Rey», fs. 474-475.

51 Memorial, f. 3.

52 Lanes y Duval (1787, pp. 30-31).

53 Memorial, f. 10. Recordemos aquí las palabras de Smith: «las relaciones de todos los viajeros convienen en lo bajo de los salarios del trabajo en China; y en la dificultad con que un trabajador Chino podía mantener su familia». Smith (1794, p. 119).
} 
Levanto coincidía con los reclamos de los sericultores peninsulares. Con los bajos impuestos comerciales, la seda madeja china gozaba de un menor precio que la producida en España. Al tejedor asiático se le pagaban bajos salarios y junto a las lógicas de comercialización el resultado era una alta rentabilidad. Al ser un producto liviano y cotizarse en base al peso de los fardos y cajones, el impuesto portuario resultaba muy bajo, por lo que la ganancia era enorme con relación a su precio relativo de mercado. ${ }^{54}$

Para el genovés, la razón del éxito del comercio chino era su amplio mercado consumidor. Por un lado, los tejidos de seda "se consumen en Nueva España mucha cantidad, que los gastan toda calidad de personas, así ricos como pobres». La seda española carecía de demanda en Nueva España, a excepción de la de color negro que la «gasta gente rica [porque] el negro de Filipinas no es tan bueno y lustroso como el de España».55 Por su parte, los de algodón:

«también valen muy baratos. Y los que llaman bocacíes sirven de aforros y las holandillas para jubones de indios y negros y los lampotes, mantas de Moro y de Bombón y de Ilocos también para aforros, camisas y manteles de gente pobre y de trabajo y los caniquíes para cuellos de toda calidad de personas. Que hay algunos muy delgados, vistosos y durables al modo de cambray de Flandes. Y la sinabafa que es el género de algodón que viene de Manila y se gasta en Nueva España más cantidad que de todos los otros lienzos de China juntos la mayor parte consumen los indios para camisas, calzones y tilmas y cobijas que las cobijas sirven como de manto a las indias y las tilmas como de capote a los indios, que apetecen mucho el dicho género de lienzo, llamado sinabafa, por ser muy blanco y lavarse con facilidad, y se le dar barato de real y medio a dos la vara y subiendo del dicho precio, gastan muy poco» ${ }^{56}$

No debemos confundirnos: cuando Levanto se refiere a la sinabafa apunta al algodón producido en Filipinas y no el de la India Oriental que será en tiempos posteriores un textil característico de la carga del galeón. Es notable la diversidad de grupos sociales que accedían tanto a la seda como al tejido de algodón filipino; productos que en la época se los conocía con el genérico término de «ropa de china». El consumo de la seda madeja y de la sinabafa superaban cualquier barrera de clase, siendo una prenda común para los esclavos, indígenas y trabajadores mineros. Aún en el caso de un escenario de desabastecimiento de lienzos de China, estos grupos habrían resistido consumir los tejidos de lino y cáñamo procedentes de Europa porque disponían de «mantas de Campeche y de la Huaxteca y otras mantillas de algodón que tienen cantidad y tejen ellos en sus casas». ${ }^{57}$ Grau y Monfalcon

54 «viene ordinariamente de Manila a Nueva España de 3 a 4 mil fardos y cajones de seda que valen mucho y dejan poco provecho a la real hacienda por venir registrados parte por cosa de poco valor y avaluarse barato conforme a los precios de Manila», Memorial, f. 3.

55 Memorial, fs. 2-3.

56 La sinabafa costaba 5 reales la pieza de tres varas en Manila. Ibidem, fs. 2-3.

57 Ibidem, fs. 2-3. 
revalidaba la opinión de Levanto porque en las minas: «los aviadores ni consumen ni pueden comprar ropa de Castilla por su calidad y valor, sino de China que es barata y de más dura y más trabajo». ${ }^{58}$

Disponemos de documentación fáctica para persuadirnos que la apreciación de Levanto era válida. En una Relación de 1609 del capitán Pedro Martínez de la provincia de Pánuco (Veracruz) se enlistan textiles y sus respectivos precios que eran utilizados por los españoles y los indios. Entre los tejidos «más ordinarios» se encontraban «la vara de paño ordinario de Puebla a siete pesos, la de raso y tafetán de la China a un peso y medio cada una, la docena de medias de China a siete pesos, las de España a quince». ${ }^{59}$ Resulta sorprendente ver que la vara de seda china utilizada por los indios de Veracruz valía menos que un tejido de producción local, de Puebla. Las medias asiáticas costaban la mitad del valor de las españolas. Un dato no menor: nos referimos a una región muy cercana al Atlántico y, a pesar de la distancia, la seda china gozaba de una cotización netamente inferior a la española. Lo que ocurrió en Nueva España se extendía hacia Guatemala y Perú. A mitad del siglo xvII, el viajero Thomas Gage decía que en Guatemala «las indias iban a la iglesia o a una visita con seda china que cubre la cabeza y toca la tierra.$^{60}$ Hacia 1605, más al sur, el gobernador de Panamá, Francisco Valverde de Mercado, confirmaba que la vara de seda china en México valía 12 reales, en el Perú 15 y en Panamá, como mucho, 30 reales; netamente inferior a la vara de seda española que la calculaba en 100 reales. ${ }^{61} \mathrm{Al}$ mismo tiempo en que Levanto escribía su Memorial, se publicaba la Descripción del comerciante portugués León Portocarrero. El genovés afirmaba que, de las mercaderías en circulación por el mercado limeño procedente de México, había mucha seda china, «y toda es ropa que se vende bien y se visten de ella los pobres porque son baratas». ${ }^{62}$ Años atrás, en 1594, el virrey peruano Hurtado de Mendoza al comparar el costo de una vestimenta compuesta con sedas chinas y otra europea, no dudó en concluir que: «un hombre puede vestir a su mujer con sedas chinas por 25 pesos mientras que no podría proporcionarle vestidos con seda española por doscientos pesos». ${ }^{63}$ El consumo socialmente heterogéneo de bienes asiáticos en Nueva España fue una característica que se prolongó hasta finales del siglo XVIII. Así lo demuestra la apreciación brindada por Rafael Dobado sobre la carga del galeón San José en el año 1777, en la que aparece una canasta de

\footnotetext{
58 «los indios y negros solo quieren lienzos de China y Filipinas, porque la vara de estos costaría real y medio mientras que los lienzos de Castilla alcanzarían los ocho reales», en «Memorial dado al rey", fs. 477.

59 Martínez [1609] (1969, pp. 153-154).

60 Gage (1980, p. 167).

61 AGI, "Carta del presidente Francisco Valverde de Mercado, 9 de Octubre de 1605», Panamá, Vol. 15, registro 6, núm. 52, f. 4.

62 Portocarrero (1620, fs. 211-212).

63 Borah (1975, p. 122).
} 
artículos asiáticos baratos y que no eran para el consumo de la elite novohispana. ${ }^{64}$

No debería sorprender que tanto Levanto como Grau y Monfalcon hayan cuestionado la idea de la imposibilidad de vender seda española en Nueva España por la exitosa competencia asiática; una premisa sostenida por los cargadores sevillanos y que la historiografía revalidó sin revisión crítica. ${ }^{65} \mathrm{De}$ acuerdo a sus apreciaciones, los tejidos de seda de Castilla, caros y de elevada calidad, se vendían y se consumían fácilmente en las Indias. El problema era su limitado comercio. El no poder enviar «más de mil fardos de seda española en cada flota hacia Veracruz», no era responsabilidad del trato transpacífico. Más bien era la propia incapacidad de Granada, Valencia y Toledo de exportar su seda ${ }^{66}$ y el límite absoluto de su mercado consumista, reducido a los españoles ricos. ${ }^{67} \mathrm{Si}$ hubo un principio de competitividad entre lo asiático y lo europeo sólo se habría ceñido al consumo suntuario; en el que los tejidos de seda china representaron una parte, bastante minúscula según la apreciación de Levanto, de la contratación asiática. Al menos en estas primeras décadas del siglo xvII, estaríamos en presencia de una complementariedad entre los flujos ultramarinos, donde la carga mayoritaria del galeón de Manila se componía de seda madeja y algodón (sinabafa) cuyo destino era un amplio mercado consumidor, imposibilitado de acceder a los efectos castellanos y europeos. ¿Por qué razón la historiografía logró construir una indisoluble asociación entre comercio chino y consumo de elite? ¿Como si los todos los productos venidos del Oriente fueran exóticos, suntuosos y de fina elaboración? Si bien Levanto no negaba el consumo de productos orientales en los círculos de alta sociedad, lo minimizaba hasta ubicarlo como un rubro marginal.

Al menos habría que repensar la composición y el perfil del comercio asiático en la temprana modernidad, porque podría ofrecer nuevas pistas sobre la naturaleza y el tipo de relación económica que se gestó entre el espacio asiático y el hispanoamericano. Si el comercio transpacífico movilizaba productos para el consumo masivo, respondiendo a las necesidades de los sectores sociales más postergados, valdría preguntarse sobre los efectos que tuvo el trato oriental con relación a los centros manufactureros locales, cuya misión era responder a la vestimenta de los grupos de bajos recursos. Las reflexiones de Levanto recuperan esa gran problemática analizada al

64 Dobado González (2014, pp. 31-33).

65 Las representaciones de los cargadores peninsulares pueden verse en Abreu (1736). Sobre la historiografía que valida la postura competitiva: Yuste (2007); Bernal (2004, pp. 485-525) y Bonialian (2012, pp. 175-198).

66 Levanto sostenía que si Nueva España superaba la demanda de mil fardos de lienzo, el tejido español se encarecería, lo que el problema se agravaría aún más; en Memorial, f. 4.

67 «Nueva España tiene poca necesidad de ropa de seda de España porque la gasta gente rica», en Memorial, f. 2. Monfalcón añadía: «Nueva España no está no tan llena de españoles y estos de tan cortas haciendas que se puede entender de ellos con las sedas», en «Memorial dado al Rey», f. 477. 
principio del ensayo: la relación entre la importación de seda madeja de China con el desarrollo manufacturero novohispano.

Levanto deducía que lo bienes importados por Acapulco eran, en su mayoría, productos semielaborados o inacabados; entendiendo por tales términos, las materias primas que ya sufrieron una primera instancia de intervención, de elaboración, pero no constituían definitivamente un bien de consumo. Para que se conviertan en un producto final, tanto la seda como el algodón requerían de un nuevo proceso de intervención en suelo novohispano, de «industrialización». Aquí tocamos una problemática fundamental que supera los objetivos del ensayo. Nos preguntamos si la relación económica de China con la América colonial, lejos de concebirse como un nexo marginal del mapa imperial, constituye una variable de explicación para el estudio del desarrollo de los obrajes y centros manufactureros novohispanos. Levanto no tenía dudas que, por su calidad y composición, la seda madeja y el algodón formaron parte de la materia prima necesaria para los obrajes de México, Puebla y Antequera. La seda producida en la Mixteca alta, no sólo era de una calidad inferior a la China, sino que no tenía la capacidad para cubrir la demanda general de tafetanes y terciopelos novohispanos. En palabras de Levanto:

«Y de la seda madeja, pelo y trama se labran en Nueva España terciopelo, terciopelado, mantos, tocas, pasamanos, y muchos tafetanes llanos, de los cuales se llevan al Perú y otras partes de las Indias, donde no llegan buenos los negros y pardos que les van de aquí [España] por podrirse en el viaje. Y hallan que la seda madeja de China es más pareja y limpia y apropiada para los dichos tafetanes y otras obras que la que llaman mixteca que se cría en Nueva España en poca cantidad menos de la que es menester para el trato que hay de seda en el reino, en el cual se sustentan de él muchas personas en la ciudad de México, de la Puebla y Antequera» ${ }^{68}$

Recordemos aquí los dichos del procurador Grau Monfalcon en lo que atañe a la relación entre los puestos de trabajo de los obrajes novohispanos y la importación e intervención de la seda madeja de China. La coincidencia con la apreciación de Levanto es elocuente: una gran porción de los tafetanes, terciopelos y mantos compuestos con seda madeja de China labrados en los obrajes novohispanos se enviaban hacia el Perú. Pero también era posible que la seda madeja transitara por Nueva España sin intervención industrial, dispuesta para su confección en los telares peruanos. ${ }^{69}$

Ahora bien, el diagnóstico de Horacio Levanto sobre los problemas de la contratación asiática en la Monarquía hispánica le permitió exponer un plan de reformas en la segunda parte de la obra. Puntualicemos su propuesta.

\footnotetext{
68 Memorial, f. 2.

69 Vale mencionar la obra del aragonés Joan Belever, Libro general de Reducciones (1597) donde se manifiesta la circulación de seda madeja al Perú vía Nueva España para el proceso de confección. Suárez (2014, pp. 24-44).
} 
a) Monopolio real o concesión del Asiento de la seda madeja a los cargadores sevillanos para su industrialización en los obrajes peninsulares. En páginas anteriores hemos advertido que el problema de la contratación asiática para España era el gran volumen de plata peruana y novohispana que salía hacia China. Se ha comprobado que en los años en que Levanto escribía su Memorial salían desde Acapulco unos 5 millones de pesos anuales, notorio fraude si tenemos en cuenta que la legislación sólo autorizaba una exportación de 500 mil pesos. ${ }^{70}$ La seda madeja de China era responsable de esta sangría metalífera, generando serios coletazos en el funcionamiento de la Carrera de Indias. Funcionarios, religiosos y mercantilistas españoles ofrecieron propuestas con vistas a resolver el conflicto. Una idea sugerida en la época era expulsar la contratación asiática de la Monarquía Hispánica. Hasta se pensó en el ilusorio plan que Filipinas cortara todo lazo con México con todas las consecuencias negativas que ello implicaría e impulsar su relación con Japón, enviando barcos con seda china para trocarla por las reservas de plata que existían en suelo nipón. ${ }^{71}$ Direccionar la contratación asiática hacia el Japón contribuiría también a que España se reubicara de manera más beneficiosa en el escenario geopolítico asiático. Lo que estaba realizando Holanda debía servir de experiencia y, a la vez, de alarma, puesto que habían sido aceptados por Japón para cambiar la plata por sedas. El pacto, que obligaba a los holandeses a disponer de sedas chinas, ya había causado ataques en los puertos de China y un peligro concreto para las Islas Filipinas. $^{72}$

La propuesta de Horacio Levanto era radicalmente diferente. El comercio de la seda madeja de China no debía marginarse, sino que debía desplazarse al corazón mismo de la Monarquía Hispánica: a la propia España. Proponía que el rey comprara en Manila mil cajones de seda por año. La carga alcanzaría unas 120 toneladas con un costo estimado de 200 a 250 mil pesos, lo que arrojaría una ganancia anual de 500 mil pesos. ${ }^{73}$ Para el genovés, el dominio estatal en la comercialización de la seda bruta de China evitaría las enormes salidas de moneda de plata hacia China desde Acapulco, incrementando las rentas reales. Si la Real Hacienda «hallase inconveniente», el Consulado sevillano se podría encargar de reunir a muchos comerciantes interesados, donde el propio Levanto participaría «de buena gana [con] 20 mil pesos» ${ }^{74}$ Con disponibilidad en España de la seda madeja de China, particularmente de la que «al presente traen de Lanquín que es buena», los

70 Una sangría metalífera excepcional habría ocurrido en 1597, año que se denunció unos 12 millones de pesos en plata peruana y novohispana llevados hacia China. Borah (1975, pp. 227-236).

71 ; «Carta del dominico Diego Aduarte sobre comercio de Filipinas», AGI, Filipinas, 85, N 34, $1619, \mathrm{~s} / \mathrm{n}$ de fs.

${ }^{72}$ Una descripción sobre el modus operandi de Holanda en el comercio de China puede verse en: «Ordenes sobre peligro de holandeses en Japón» (1611), AGI, Filipinas, 329, L. 2, fs. 140-141.

${ }^{73}$ Memorial, f. 5.

74 Ibídem, f. 9. 
vecinos de Castilla, Andalucía y León la elaborarían en sus obrajes con destino al mercado español y al de las Indias:

«Podría dárseles la seda madeja de 36 a 40 reales de libra a los vecinos de España; cuando la que ahora se proveen ni por 55 reales la tienen y han dejado muchos de labrar» ${ }^{75}$

A Levanto no le preocupaba que España abandonara sus tierras de cultivo de seda o dejara de cultivar los árboles de morera. Tampoco daría curso a las propuestas de importar semillas de gusano de seda de Lanquín para su cultivo en tierras españolas. Las ideas expuestas en páginas anteriores dadas por el gobernador de Filipinas, Juan de Silva, o del procurador general de Filipinas de 1610, Ríos de Coronel, no habían resultado exitosas. El planteo de Levanto era aún más controvertido: España debía elaborar tejidos con la seda madeja china para así sustituir la enorme importación de tejidos que se hacían desde Flandes o de Italia. Su frase «es menos daño que entren sedas por labrar que labradas» no era sino un profundo cuestionamiento a la dependencia española sobre los centros manufactureros de Holanda, Inglaterra o de la misma Francia. ${ }^{76}$ Sólo así se evitaría la sujeción económica que sufría España con las potencias europeas; una balanza comercial que propiciaba el drenaje de la plata americana hacia Inglaterra, Francia y Holanda. La misión de España era elaborar textiles con seda oriental para suplir los pedidos del mercado interno y de otras plazas mercantiles de la Monarquía. Esto era factible porque al momento en que Nueva España tenga prohibido importar libremente seda madeja y careciendo sus obrajes del insumo, el mercado consumidor hispanoamericano dependerá del abastecimiento peninsular. Ahora bien, si Levanto insistía en la incapacidad de producir seda española para el mercado, los vecinos de Sevilla y los sericultores peninsulares lo contradecían. La idea de Horacio Levanto de importar seda china al mercado hispalense venía a enfrentarse con la posición de los sericultores peninsulares. Estamos en presencia del conflicto representado entre producción y comercio, entre el Consulado integrado por los más ricos comerciantes de ultramar (donde Levanto sería la más fiel expresión) y los sectores productivos del reino peninsular.

b) Que se le prohíba al consulado de la ciudad de México la importación de la seda madeja de China por el circuito del galeón de Manila. Para que el estanco real de la seda madeja de China fuera factible se requería anular su importación por Acapulco ${ }^{77}$ La medida no era más que un notable golpe al privilegio detentado por los comerciantes de la ciudad de México; corporación que dominaba el flujo transpacífico. Si por alguna circunstancia resultaba necesario internar la seda madeja al mercado novohispano sólo se toleraría como máximo un cuarto de la carga (250 cajones de mil) y el «resto (750 cajones)

\footnotetext{
75 Ibidem, f. 5.

76 Ibidem, f. 12.

77 «que desde la isla de Luzón a Nueva España no se pudiera navegar tejido alguno de seda», Memorial, f. 4.
} 
transitaría hasta Veracruz para su reexportación al reino de España». ${ }^{78}$ Levanto aclaraba que, a diferencia de las sedas, se autorizaría el comercio de los lienzos de algodón, pues no sólo había que garantizar el consumo social ampliado de los «más pobres» del virreinato novohispano, sino que «ocupa muy poco» espacio en el galeón de Manila, por lo que no provocaría sustanciales salidas de plata hacia China. Mientras que 4 mil fardos de lienzo de algodón costaban tan sólo 300 mil pesos en Manila, la sedas de China «ocupan mucha cantidad de moneda», drenando millón y medio por año. ${ }^{79}$

Si Nueva España se había convertido en el epicentro del comercio asiático era necesario desplazarla a una posición de menor privilegio, de una mayor dependencia económica con la Península Ibérica. Su ubicación central le había permitido contar con el insumo oriental para así elaborar textiles dirigidos al consumo socialmente amplio de su mercado interno, extendiéndose incluso hasta el Perú. ${ }^{80} \mathrm{Si}$ se marginaba al consulado de la ciudad de México de la contratación de seda china, se evitarían las salidas enormes de plata hacia el Oriente. Pero ¿cómo lograr el desplazamiento a un segundo plano de México? Para Levanto, un nuevo modelo de circulación de la seda madeja de China entre Filipinas y España lo haría posible. Llegamos así a la tercera medida propositiva de Levanto.

c) Nueva función de Panamá y Portobelo en el comercio directo entre España y Manila. El nuevo tejido comercial propuesto para que España acceda a la seda madeja resulta, a nuestro juicio, el apartado más débil de la argumentación. Veamos paso a paso el derrotero propuesto. El galeón de Manila ya no sería el conducto mercantil para la movilización del textil. El ciclo se iniciaría desde Cádiz hacia Portobelo, con el envío de barcos de infantería y «gente de mar». Al llegar al bastión del monopolio comercial, la tripulación se internaría por Panamá hasta llegar al Pacífico. De sus costas occidentales saldrían los navíos del Mar del Sur rumbo a Manila. La escala en Panamá permitiría la recolección de bastimentos y recuperar la salud de los marineros. Si priorizaba la escala de Panamá era porque Levanto desechaba la conexión Veracruz/Acapulco; un prolongado derrotero de 150 leguas que lo desacreditaba por sus adversidades climáticas y sus complicaciones de sus vías terrestres. Mientras el tiempo de navegación por el eje España-MéxicoManila lo estimaba en un año, la ruta España-Panamá-Manila no superaría, según su parecer, los 5 meses. ${ }^{81}$ Por esos tiempos, surgían propuestas de utilizar como escala el Cabo de Hornos o el de Buena Esperanza para concretar la relación directa entre España y China. ${ }^{82}$ Sin embargo, para

78 Ibidem, f. 15.

79 Ibidem, f. 4.

80 Bonialian (2014, pp. 27-82).

81 «Parece cierto y evidente que el viaje por la vía de Portobelo y Panamá es de menos costa, más cierto, breve y segura que por Nueva España, ni que por la India», Memorial, fs. 16-17.

82 Para una aproximación sobre el papel del Cabo de Hornos en las travesías y expediciones, véase: Bernabeu (1992, pp. 1-76). 
Levanto estos derroteros sólo tenían consideración para una navegación de mercadería pero no de infantería.

Los navíos que salieran desde Panamá hacia Manila en búsqueda de la seda madeja retornarían a Acapulco; surgidero que continuaría siendo el único puerto permitido para su despacho. ${ }^{83}$ Se infiere aquí la voluntad de Levanto por la desaparición del galeón de Manila o, al menos, la de ser uno de los tantos navíos que se movilizarían por la vía transpacífica. Los proyectados navíos de la mar del Sur retornarían hacia Acapulco con la seda madeja; paralelamente, el galeón de Manila cargaría sólo algodón y otros productos permitidos, pero sin el comercio de seda madeja.

Levanto depositaba su confianza en un puñado de jueces y funcionarios para la fiscalización y el control del movimiento de la seda madeja. Ellos tendrían la función de evitar el fraude del insumo por tierras novohispanas. Dos mil ducados bastarían para solventar el salario de un juez al desembarcar la seda en Acapulco, el traslado a Veracruz y su salida final en las flotas rumbo a España. ${ }^{84}$ Levanto le otorgaba participación a los mercaderes del Perú, concediéndoles una misión limitada en el plan. Ellos podrían colaborar con capital y navíos para los viajes que se realizarían desde Panamá hacia Manila, pero deberían regresar exclusivamente a Acapulco, cumpliendo el estanco real o asiento peninsular. Llegados a Acapulco, los peruleros estarían autorizados para cargar bienes locales permitidos (no así los bienes chinos) rumbo al puerto del Callao. Cuesta creer que los mercaderes limeños se limitaran a esta regla, cuando sabemos que por estas décadas gozaban de una notable movilidad para adquirir bienes asiáticos tanto en Filipinas como en Acapulco. De hecho, al disponer de la plata potosina, producción en pleno auge por estas décadas, los peruanos llegaron a comprar la seda china a través de derroteros directos entre Perú y el archipiélago. Asimismo, también podemos confirmar que desde 1590 hasta 1620 existió una efectiva participación de los peruleros en las ferias de Acapulco, realizando cargas ilícitas de seda china hacia el Perú. ${ }^{85}$

Portobelo tendría un papel fundamental en el comercio de la seda madeja de China. Levanto lo ubicaba como el sitio neurálgico para un renovado comercio asiático. Existían motivos geopolíticos para proponer esta transformación. Uno de ellos era el de reforzar el comercio peruano de los galeones; circuito oficial que por estos tempranos tiempos sufría contratiempos a raíz del contrabando de mercaderías chinas y europeas generado desde Acapulco hacia El Callao. ${ }^{86}$ La nueva vía de circulación de la seda madeja de China era, en el fondo, un fuerte impulso a la Carrera de Indias con su sistema de flotas y galeones. Apuntaba a erosionar la centralidad novohispana y a la de sus mercaderes de la ciudad de México.

83 «Las naves que fueren de Panamá a Manila no vuelvan a otro puerto de Acapulco», Memorial, f. 21.

84 Memorial, fs. 13-14.

85 Iwasaki Cauti (1992); Flores (1995, pp. 377-409).

86 Vila Vilar (1982, pp. 275-340); Suárez (1995); Bonialian (2014, pp. 11-41). 


\section{CONCLUSIONES}

Las líneas del pensamiento económico de Levanto son elocuentes. El estado metropolitano debía intervenir el mercado libre, en el juego de la oferta y demanda de bienes. Para mantener la relación de dominio colonial era necesario romper con la tendencia productiva de bienes en México, favorecido por la importación de la seda madeja de China. Para ello había que fomentar y re-direccionar la economía filipina de exportación hacia España. A través de un claro perfil proteccionista, España iniciaría un proceso de sustitución de importaciones europeas, elaborando textiles compuestos de seda oriental. Estos tejidos responderían al consumo interno español como al de los mercados de las Indias, reforzando la relación de dependencia trasatlántica de las Indias.

Por otro lado, es necesario comenzar a cuestionar seriamente la idea de un comercio asiático reducido tan sólo al consumo de elite. A partir de evidencia cualitativa, hemos logrado constatar un tráfico oriental de un consumo cotidiano y socialmente ampliado en el rubro de los textiles. Esta reformulación del consumo por el eje transpacífico nos coloca ante un nuevo desafío con vistas a reinterpretar el tipo de integración del comercio asiático en el mapa general del comercio colonial. En segundo lugar, hemos advertido la íntima relación que existió entre el insumo oriental de la seda madeja de china con el fenómeno manufacturero y obrajero novohispano y peninsular. El comercio asiático, lejos de ser un elemento secundario en la economía de la Monarquía Hispánica, llegó a influir en su plano productivo. Si en el caso de Nueva España, la importación del producto asiático propició el proceso «industrial», en el caso peninsular lo condicionó.

Por último, el Memorial de Levanto manifiesta la gravitación que cumplía el comercio asiático y, en él la seda madeja de China, por todo el mapa de la Monarquía. España retornaría a su posición de centralidad comercial a partir de la implementación de cambios en materia geopolítica. Se eliminaría la posición de epicentro de México en la contratación asiática, al re-direccionar el comercio de la seda china directamente hacia España. Una de las manifestaciones más representativas de esta medida sería la marginación del consulado de la ciudad de México al trato de la seda china y un papel más revitalizador del comercio español. Se incorporarían los espacios de Panamá y del Perú en el trato oficial, con el fin de revitalizar las rutas y los agentes comerciales peninsulares que actuaban en el comercio trasatlántico.

\section{FUENTES}

Álvarez De Abreu, A. (1736): Extracto historial del expediente que pende en el Consejo Real y Supremo de Indias de la ciudad de Manila y demás islas Filipinas, imprenta Juan de Ariztia, Madrid.

Archivo General De Indias, Sevilla (AGI).

Archivo General De La Nación De México (agnM). 
Levanto, H. (1620-22): Memorial sobre el trato de la China con Nueva España y estos Reinos. Dirigido al Señor Don Fernando Carrillo, Caballero del hábito de Santiago y Presidente del Real y Supremo Consejo de Indias, Biblioteca Digital Nacional de España (BN), R/17.270.

Gage, T. (1980): Viajes a la Nueva España, La Habana, Casa de las Américas..

Grau Y Monfalcon, J. (1637): «Memorial dado al Rey en su Real Consejo de las Indias por D. Juan Grau y Monfalcon, procurador general de las Islas Filipinas, sobre las pretensiones de la ciudad de Manila y demás del archipiélago en su comercio con Nueva España», Colección de Documentos inéditos relativos al descubrimiento, conquista y organización de las antiguas posesiones españolas de América y Oceanía, por Luis Torres de Mendoza, Madrid, 1866, tomo VI, fs. 345-483.

Grau Y Monfalcón, J. (1637): «Justificación de la conservación y comercio de las islas Filipinas», Madrid, en Álvarez de Abreu, Extracto Historial del expediente que pende en el Consejo de Indias a instancias de la ciudad de Manila y demás provincias, Madrid, Juan de Ariztia, 1736, pp. 64-78.

Martínez, P. (1609): «Descripción de los pueblos de la provincia de Panuco sacadas de las relaciones hechas por Pedro Martínez, capitán y alcalde mayor de aquella provincia», Colección de documentos inéditos relativos al descubrimiento, conquista y organización de las antiguas posesiones españolas de América y Oceanía, NendelnLiechtenstein, 1969, Krauss Reprint, vol. IX, pp. 150-166.

Portocarrero, L. (1620): Descripción general del Reino del Perú, en particular de Lima, Biblioteca Nacional de Francia (BNF), Ramo Espagnol 280.

\section{BIBLIOGRAFÍA}

Álvarez, L. A. (2013): «E la nave va. Economía, fiscalidad e inflación en las regulaciones de la carrera de la Mar del Sur», en S. Bernabeú, y C., Martínez Shaw (eds.), Un océano de seda y plata: el universo económico del Galeón de Manila. Sevilla: Colección Universos Americanos, Consejo Superior de Investigaciones Científicas, pp. 25-84.

AsSADOURIAN, C. S. (1982): El sistema de la economía colonial: mercado interno, regiones y espacio económico. Lima: Instituto de Estudios Peruanos.

BARRET, W. (1990): «World Bullion Flows, 1450-1800», en Tracy James (coord.), The Rise of Merchant Empires (Long Distance Trade in the Early Modern World, 1350-1750). Cambridge: Cambridge University Press, pp. 240-252.

Bernabeu, S. (1992): El Pacífico ilustrado. Del lago español a las grandes expediciones. Madrid: Mapfre.

Bernabeu, S. y Shaw, C. M. (eds.) (2013): Un océano de seda y plata: el universo económico del Galeón de Manila. Sevilla: Colección Universos Americanos, Consejo Superior de Investigaciones Científicas, Sevilla.

Bernal, A. M. (2005): España, proyecto inacabado. Costes/beneficios del imperio. Madrid: Marcial Pons.

Bernal, A. M. (2004): "La carrera del Pacífico: Filipinas en el sistema colonial de la carrera de Indias», en Cabrero L. (coord.), España y el Pacífico. Legaspi, Madrid: Sociedad Estatal de Conmemoraciones Culturales, tomo I, pp. 485-525.

Bethany, A. y Yun-Casalilla, B. (eds.) (2014): Global Goods and the Spanish Empire, 1492-1824. Circulation, Resistence and Diversity. Nueva York: PalgraveMacmillan. 
Bonialian, M. (2014): China en la América colonial. Bienes, mercados, comercio y cultura del consumo desde México hasta Buenos Aires. Buenos Aires-México: Biblos-Instituto Mora.

Bonialian, M. (2012): El Pacífico Hispanoamericano. Política y comercio asiático en el Imperio español (1680-1784). México: El Colegio de México.

Bonialian, M. (2014): «La Contratación de la China por la América colonial a principios del siglo XVII». Boletín del Instituto de Historia Argentina y Americana Dr. Emilio Ravignani, 3era. Serie, 1 semestre. Buenos Aires: Instituto Ravignani, $N^{\circ} 40$, pp. 11-41.

Borah, W. (1975): Comercio y navegación entre México y Perú en el siglo XVI. México: Instituto Mexicano de Comercio Exterior.

Borah, W. (1963): «El origen de la sericultura en la Mixteca Alta». Centro de Estudios Históricos, El Colegio de México (ed.), Historia Mexicana. México: El Colegio de México, $\mathrm{N}^{\circ} 40$, pp. 1-17.

Brewer, J. y Porter, R. (coords.) (1994): Consumption and the World of Goods. Londres: Routledge.

Carmagnani, M. (2012): Las Islas de lujo. Productos exóticos, nuevos consumos y cultura económica europea, 1650-1800. México: El Colegio de México-Marcial Pons Historia.

CRoss, H. (1983): «South American Bullion Production and Export 1550-1750», en J. F. Richards (ed.), Precious Metals in the Later Medieval and Early Modern World. Durham: Carolina Academic Press, pp. 397-423.

Chaunu, P. (1960): Les Philippines et le Pacifique des ibériques (XVI, XVII, XVIII). Introduction methodologique et indices d'activité. Paris: Sevpen.

DE VRIES, J. (2010): «The Limits of Globalization in the Early Modern World», en, The Economic History Review 63 (2), pp. 710-733.

Díaz Blanco, J. M. (2014): «Pensamiento arbitrista y estructuras institucionales en la Carrera de Indias (siglo XVII); entre la desincentivación y la represión». Anuarios de Estudios Americanos. Sevilla: España 71 (1), pp. 47-77.

Dobado González, R. (2014): «La globalización hispana del comercio y el arte en la Edad Moderna». Estudios de Economía Aplicada. Madrid: vol. 32-1, pp. 13-42.

Flores, R. (1995): «El secreto encanto de Oriente. Comerciantes peruanos en la ruta transpacífica (1590-1610)», en Scarlett O'Phelan Godoy y Carmen Salazar Soler (eds.), Passeurs, mediadores culturales y agentes de la primera globalización en el mundo ibérico, siglos XVI-XIX. Lima: Pontificia Universidad Católica del Perú, pp. 377-409.

FlynN, D. y GiRÁLDEZ, A. (2014): «Los orígenes de la globalización en el siglo XVI», en Hausberger, Bernd e Ibarra, Antonio (coords.), Oro y plata en los inicios de la economía global: de las minas a la moneda. México: El Colegio de México, pp. 29-76.

FlynN, D. y Giráldez, A. (eds.) (1997): Metals and Monies in an Emerging Global Economy. Aldershot: Hampshire.

Frank, A. G. (1998): ReOrient: Global Economy in the Asian Age. Londres: University of California Pres.

García Fuentes, L. (1997): Los Peruleros y el comercio de Sevilla con las Indias, 1580-1630. Sevilla: Universidad de Sevilla.

Gipouloux, F. (2009): La Méditerranée asiatique. Villes portuaries et réseaux marchands en Chine, au Japon et en Asie du Sud-Est xvie-xxie si'ecle. Paris: cnrs-editions.

Grijalva, M. M. (1988): «La política textil en México y Perú en la época colonial». Historia Mexicana. México: El Colegio de México, vol. 38 (2), pp. 283-321.

Iwasaki Cauti, F. (1992): Extremo Oriente y Perú en el siglo XVI. Madrid: Mapfre. 
Hausberger, B. e Ibarra, A. (coords.) (2014): Oro y plata en los inicios de la economía global: de las minas a la moneda. El Colegio de México: México.

Lanes y Duval, J. Duval, y Duval, J. (1787): Arte de la cría del gusano de seda. Madrid: Imprenta Real.

LeE, J. (1999): «Trade and Economy in Preindustrial East Asia, 1500-1800: East Asia in the Age of Global Integration». Journal of Asian Studies 58 (1), pp. 2-26.

Marichal, C. (2006): «The Spanish American Silver Peso: Export Commodity and Global Money of the Ancien Regime (16th-18th centuries)», en Steven Topik, Carlos Marichal y Zephyr Frank (coords.), From Silver to Cocaine: Latin American Commodity Chains and the Building of a World Economy (XVI-XXth Centuries). Durham: Duke University Press, pp. 25-52.

Schurz, W. (1960): The Manila Galleon. New York: E. P. Dutton \& Co.

O’rourke, K. y Williamson, J. (2004): «Once More: When Did Globalization Begin?». European Review of Economic History 8, pp. 109-177.

Pomeranz, K. (2000): The Great Divergence. Europe, China, and the Making of the Modern World Economy. Princeton: Princeton University Press.

Sмiтн, A. (1794): Investigación de la naturaleza y causas de la riqueza de las naciones. Valladolid: Viuda e Hijos de Santander.

Suárez, M. (1995): Comercio y fraude en el Perú colonial. Las estrategias mercantiles de un banquero. Lima: Instituto de Estudios Peruanos.

SuÁRez, M. (2014): «Reforma, orden y concierto en el Perú del siglo XVII: el arbitrio de Joan de Belveder». Anuario de Estudios Americanos, Sevilla: Escuela de Estudios Hispanoamericanos de Sevilla 71, pp. 25-44.

Tepaske, J. (1983): "New World Silver, Castile y Philippines 1590-1800», en J. F. Richards (coord.), Precious Metals in the Later Medieval and Early Modern World. Durham: Carolina Academic Press, pp. 425-445.

Vila VilaR, E. (1982): «Las ferias de Portobelo: Apariencia y realidad del comercio con Indias». Anuario de Estudios Americanos, Sevilla: Escuela de Estudios Hispanoamericanos de Sevilla. tomo xxxix, vol. 1, pp. 275-340.

Von GLAHn, R. (1996): Fountain of Fortune: Money and Monetary Policy in China, 1000-1700. Berkeley: University of California Press.

Von Glahn, R. (1996): "Myth and Reality of China's Seventeenth-Century Monetary Crisis». The Journal of Economy History, vol. 56 (2), pp. 429-454.

Yuste, C. (1984): El comercio de Nueva España con Filipinas 1590-1785. México: INAH.

Yuste, C. (2007): Emporios transpacíficos. Comerciantes mexicanos en Manila 1710-1815. México: UNAM, 2007. 